\title{
O vestido vermelho: consumo, cultura material e comunicação intersensorial na feira do Guamá, Belém-Pará
}

\section{The red dress: consumption, material culture and intersensory communication at the fair in Guamá, Belém-Pará}

Marina Ramos Neves de Castro - Doutora em Antropologia pelo Programa de Pós-Graduação em Antropologia (PPGA) da Universidade Federal do Pará (UFPA). Professora da Faculdade de Comunicação da UFPA. E-mail: mrndecastro@gmail.com

\section{Resumo}

Este trabalho se propõe a interpretar os processos de sociação em um grupo de feirantes na feira do Guamá, em BelémPA. Partimos da compreensão de que as práticas de consumo conformam processos de sociação (SIMMEL, 2006), processos estes que se reverberam através da comunicação intersensorial ali estabelecida. Com apoio de Miller (2007, 2008), discute-se como o consumo e a cultura material contribuem para a construção de intersubjetividades (CASTRO, F., 2017) e de processos de comunicação intersensorial (CASTRO, M., 2020), e como estes corroboram para a produção e/ou incremento de reciprocidades (MAUSS, 1974). Observamos que as relações recíprocas que estabelecemos, e através das quais nos comunicamos, estão permeadas pela intersensorialidade, ou seja, pela comunicação através da qual os sentidos do corpo, providos de cultura, são agentes fundamentais para a realização da intersensorialidade. Reflete-se sobre como as coisas destacam-se como elementos de partilha e de reciprocidade entre aqueles que participam desses processos de sociação.

\section{Palavras-chave}

Consumo. Cultura material. Comunicação intersensorial, Intersubjetividade.

\begin{abstract}
This work proposes to interpret the sociation processes in a group of marketers at the fair of Guamá, in Belém-PA. We start from the understanding that consumption practices and material culture make up sociation processes (SIMMEL, 2006), processes that reverberate through the intersensory communication established there. With the support of Miller $(2007,2008)$ we discuss how consumption and material culture contribute to the construction of intersubjectivities (CASTRO, F., 2017) and the intersensory communication processes (CASTRO, M., 2020) and how they corroborate for the production and / or increase of reciprocities (MAUSS, 1974). We observe that reciprocal relationships that we establish, and through which we communicate, are permeated by intersensoriality, that is, by that communication through which the body's senses, provided with culture, are fundamental agents for the realization of intersensoriality. It reflects on how things stand out because they are elements of sharing and reciprocity among those who participate in these sociation processes.
\end{abstract}

\section{Keywords}

Consumption. Material culture. Intersensory communication. Intersubjectivity. 


\section{INTRODUÇÃO}

Acompanhei Amanda na feira do Guamá quando ela estava à procura de um vestido novo, especial, para usar na noite de 24 de dezembro, Natal em família. Ela disse-me que quando saiu da casa pensou em comprar um vestido branco que tinha visto por ali, na feira, alguns dias antes, quando passara de ônibus justamente em frente ao prédio dos produtos industrializados, onde se localizam os feirantes que vendem, em seus boxes, roupas novas. No entanto, ao chegar à feira viu o vestido vermelho no boxe ao lado do qual ela tinha notado o vestido branco e, mesmo ainda pensando em levar o branco, decidiu experimentar o vermelho primeiro. A intenção, a partir de então, era experimentar ambos os vestidos, e como o branco já estava como certo para a compra, Amanda decidiu começar sua escolha experimentando o vermelho.

Acercou-se dela a vendedora do boxe ao lado, dona Gilda; a vendedora do vestido vermelho, dona Meire; e eu, que estava ali acompanhando o quotidiano da feira no espaço concedido à vestimenta e aos produtos industrializados. E foi justamente na entrada de Amanda nesse ambiente que passei a acompanhá-la.

Enquanto Amanda olhava-se ao espelho, seu olhar e seus movimentos de corpo demonstravam satisfação. Seu olhar anunciava que o vestido lhe caíra perfeitamente bem, o que evidenciava uma satisfação em atender ao desejo de se sentir bela. Bela, também, a partir do olhar de aprovação do outro - nós que acompanhávamos sua escolha.

Sim, os movimentos do corpo, à direita e à esquerda, o virar da cabeça em oposição ao corpo, os leves semicírculos que fazia com os quadris ao movê-los, as expressões de satisfação de seu rosto, acrescentando a isso uma expressão que perpassava a vontade de sorrir, mas que, diante da plateia, por pudor, talvez, precisava ser contida. Talvez não. Tratava-se de uma interação que se realizava através de uma série de dispositivos comunicativos que se estabeleciam tanto através da comunicação verbal, visual e corporal, como por meio de uma comunicação intersensorial, que perpassava as trocas e influências entre os sentidos do corpo do eu e do outro, assim como entre os sentidos e o aparato cultural, ou seja, intersubjetivo, do qual fazíamos parte.

Passaram-se assim, de quinze a vinte minutos, e Amanda seguia ouvindo comentários intercalados de dona Gilda e Meire - as proprietárias das mercadorias ali expostas para serem vendidas, respectivamente as vendedoras do vestido branco e vermelho - enquanto experimentava o vestido vermelho. Amanda parecia ter decidido. Por isso resolveu não experimentar o vestido branco; o vestido que desejava há muito tempo e que a trouxera até ali. A peça que agora vestia, e que sentia, já não era o desejado vestido branco, mas o vermelho. 
Ali, no momento da experimentação da vestimenta, o que estava consubstanciado naquela peça vermelha, com molde acentuado e em elastano ${ }^{1}$ grosso, colado ao seu corpo, com um decote pronunciado nas costas, era a materialização de um desejo subjetivo que, por certo, Amanda não queria, ou ainda não podia ou mesmo precisava evidenciar em palavras, mas que os movimentos de seu corpo e as expressões contidas em seu rosto nos levavam a interpretar: seus sentimentos de prazer e de desejo diante daquele artefato.

Embora, aparentemente, ela já tivesse decidido pela compra do vestido vermelho, tomou seu tempo olhando-se nele, com ele. Ao experimentar, levantava os braços na altura do ombro, rodava levemente o corpo, de um lado para o outro para se olhar de lado e olhar como o vestido tinha ficado atrás; alisava-o com as mãos e com os olhos, primeiramente na parte da frente, passando a mão da barriga aos quadris, passando pela cintura, em movimentos levemente ora côncavos ora convexos, a depender da parte do corpo e do vestido a ser tocado; depois, passava as mãos nas costas, já em um movimento convexo, descendo-as até a bunda ${ }^{2}$; alternando entre as palmas e as costas das mãos. Distanciava levemente os braços do corpo a fim de melhor apreciar o vestido assentado nele. O prazer contido na visão era levado ao tato. Cada parte de seu corpo evidenciada em seu olhar era levada ao toque de suas mãos, em um alisar do tecido do vestido. Isso tudo era feito na frente das vendedoras e daqueles que a rodeavam, eu e outra senhora que veio encontrá-la, e uma outra passante que parava alguns minutos para apreciar a cena e acabava por fazer um pequeno comentário: "tá lindo".

Virava-se para um lado e outro, em movimentos suaves para se olhar, sempre em uma nova posição, procurando apreciar cada pequena parte de seu corpo. Alguns de seus movimentos eram suaves e seu corpo balançava doce e levemente; algumas paradas de movimento pareciam se fazer necessárias; assim, enquanto sacudia a cabeça e fazia seu cabelo longo balançar de um lado a outro das costas, deixava seu corpo parado na diagonal como se estivesse dançando discretamente, usando apenas e levemente a cabeça de maneira ritmada. Essa maneira de se mover, de balançar o corpo, as expressões em movimento contínuo em seu rosto, mostrounos o prazer que ela estava sentindo em experimentar o vestido.

O barulho era intenso, passara há pouco um carro de som com a propaganda de uma loja de material de construção que fica próxima, logo ali na esquina. O calor estava forte, era quase 11 horas da manhã e o ambiente estava

\footnotetext{
Fibra sintética de grande elasticidade muito utilizada em vestimentas populares, também é conhecida como laicra ou bycra, de imensa popularidade no mercado de varejo e atacado em Belém. Há enormes variações de cores, texturas e elasticidades na produção dessas peças deste tipo de tecido.

2 Bunda e bumbum são os termos usados coloquialmente nessa feira, preferido a nádegas.
} 
iluminado por lâmpadas elétricas frias, na tentativa de não aumentar o calor. O teto de amianto e algumas telhas transparentes acentuavam o calor. Alguns ventiladores, colocados pelas feirantes, o atenuavam, proporcionando certo conforto e ajudando a evitar o desconforto dos clientes.

O ambiente produzia sensações táteis, olfativas - cheiro de roupa nova, por exemplo -, visuais, sonoras, todas ambivalentes, difusas, às vezes confusas. Sensações sinestésicas que poderiam facilitar ou dificultar a negociação. A questão, no entanto, era que aquelas sensações eram partilhadas, ou melhor, faziam parte, de uma intersensorialidade ${ }^{3}$ que se produzia através da comunicação, de uma cultura intersensorial do $e u$, do eu com o outro, do eu com o ambiente, e outras possíveis ainda, como do eu com o outro e com o ambiente. Podemos compreender que as sensações sinestésicas que se produzem em uma escala sensorial individual (PINK, 2009, 2010) ocorrem e tomam forma a partir do constructo social no qual o indivíduo está inserido, de maneira intersubjetiva, como processo gerador de cultura e de sentidos do corpo.

Este trabalho é um dos resultados de pesquisa que ocorreu entre os anos de 2011 e 2018 sobre a experiência sensível em uma feira de Belém-Pará, a feira do Guamá. Com ele procurei compreender como as relações baseadas no gosto engendram processos de reciprocidade e, consequentemente, de sociação. Este artigo apresenta um resultado específico obtido em campo durante o processo da pesquisa com apoio da etnografia sensorial. Busca-se uma abertura interdisciplinar, construindo um diálogo entre a Antropologia, a Sociologia e a Comunicação para melhor situar fenômenos culturais complexos como o da intersensorialidade.

Nesse processo, usei como suporte reflexivo o referencial da etnografia sensorial (PINK, 2009, 2010), o de intersensorialidade (CASTRO, M., 2018), a categoria experiencial do ser afetado (FAVRET-SAADA, 2005, 2012), Simmel (1993, 2006), Miller (1987, 2007, 2009), Castro e Castro (2018), Mauss (1974) e outros pensadores que, a partir de minha leitura e experiência no campo e na construção etnográfica, corroboraram para esta reflexão.

\footnotetext{
Compreendemos que o fenômeno da intersensorialidade ocorre - a partir do entendimento de que os sentidos do corpo, as percepções e seus valores, seriam o resultado de certa vivência e experiência cultural, no lugar e na temporalidade examinada (CLASSEN, 1997; CORBIN, 1990, 1991; HOWES; MARCOUX, 2006) - como o resultado do processo de trocas de nossas impressões, de nossas sensações, quando nos comunicamos ao utilizar os sentidos, aqueles que habitam o corpo - que é um médium - produtor e receptor concomitante das informações que nos invadem através dos sentidos do corpo - da visão, da audição, do olfato, do tato, do paladar, e "pela sinestesia provocada por estar ali, naquele ambiente, experienciando essas informações sensoriais e produzindo uma comunicação intersensorial entre o eu e o outro" (CASTRO, M., 2020, p. 4).
} 


\section{O CONSUMO: A NEGOCIAÇÃO ENTRE A SATISFAÇÃO DO PRAZER E AS EVIDÊNCIAS DA TROCA}

Ao olhar-se de costas, Amanda procurava ver como o vestido lhe caía e dizia que gostava do "decote redondo [na parte de trás] e também do decote da frente... e o vermelho é muito lindo para o Natal!" . A venda estava quase certa, mas o quase não permitia a conclusão da venda. Amanda não perdeu de vista seu objetivo naquela compra, mas não queria pagar mais do que se propunha. Na tentativa de estabelecer um lugar de negociação, e sabendo que, até então, tinha exposto o desejo de satisfação que poderia atrapalhar uma barganha, ensaiou uma dúvida quanto à aquisição do referido vestido. Rapidamente, dona Meire, a vendedora do vestido vermelho, que não queria perder a venda, se posicionou, e ambas, feirante e freguesa, estabeleceram um diálogo sutil.

Amanda perguntou sutilmente pelo preço do vestido, "um pouco salgado", e a vendedora ${ }^{5}$, atenta, acenou um desconto. O diálogo era intercalado com pequenas pausas entre um enunciado, nem sempre falado, e outro, de ambos os lados. Nem Amanda queria mostrar sua real vontade de comprar o vestido vermelho, em detrimento do branco, nem a vendedora queria mostrar sua ânsia em vendê-lo.

Nesse diálogo construído por pequenas interjeições, movimentos de corpos, expressões faciais e corporais, Amanda voltava-se constantemente para o espelho, às vezes deixando escapar sua satisfação, às vezes a escondendo através de expressões corporais e faciais que injetavam dúvidas no outro. Às vezes, ainda, desejando captar as percepções de quem a olhava através de seus comentários. Desejava, assim, apreender sua imagem através das expressões e das falas do outro; apesar de, outras vezes, evitar, discretamente, o escrutínio da vendedora.

Por fim, afastou-se levemente e olhou-se em diagonal, deixando transparecer que o vestido lhe caíra bem, "como uma luva", disse dona Gilda. Alguns silêncios foram interpostos por todos, nesse diálogo. A venda parecia longa! A vendedora comentou com os outros participantes, em um diálogo na diagonal, sem olhar nos olhos dos interlocutores, pequenas observações sobre como o vestido tinha caído bem em Amanda, como o decote e a cor a deixavam "muito bem". Depois de muitas frases curtas, muitos silêncios entre as duas mulheres, muita especulação e vários elogios da audiência - eu, Jussara, dona Gilda, e mais

4 Amanda, em entrevista concedida à pesquisadora na feira do Guamá. Belém, 16 dez. 2016. Pseudônimo para proteger minha interlocutora, ainda que o uso da entrevista tenha sido autorizado.

5 Importante observar que nessa área da feira, quem ali vende, vê-se ora como feirante, ora como vendedora de roupa; isso varia de acordo com as circunstâncias. 
aquelas pessoas que passavam e a viam admirar-se no vestido -, Amanda decidiu fechar o negócio e comprar o vestido.

Decidida a venda, Amanda se voltou para o vestuário, fechou a cortina e trocou de roupa. O pequeno público que naquele momento a acompanhava, apesar de não se conhecerem, dispersou-se delicadamente. Em alguns segundos, Amanda e a vendedora fecharam o negócio. Amanda saiu com o vestido em sua bolsa, dizendo adeus a todos com um sorriso largo no rosto. Agora, ela não precisava disfarçar a satisfação, presente em seu sorriso e nos movimentos expansivos de seu corpo, de ter comprado o vestido, pois "se eu mostrar que estava feliz. com a compra, dificilmente teria um desconto assim, certo?"6 - ela estava se referindo ao desconto de $\mathrm{R} \$ 10,00$ que havia conseguido na compra do vestido.

Retorno ao box de Meire, onde estava sentada a conversar quando Amanda entrou ali para comprar um vestido, e quando passei a acompanhá-la nesse processo de compra e venda, nessa sociação ${ }^{7}$ construída - nessa sociação possível, conformada através de elementos e conteúdos como a pesquisadora, como o vestido, o espelho, o box e o conjunto de boxes, o movimento dos corpos, as expressões, o tipo de sala de montagem no qual estávamos todos. Cada um desses elementos compunha aquela forma social (SIMMEL, 1993), e é nessas formas sociais que se conforma o mundo da vida, onde construímos os sentidos que permitem as relações de troca no fluxo dos processos comunicativos intersensoriais, e que criam, processam e reverberam sentidos e cultura.

Jussara, filha de Meire, acompanhara a venda e, portanto, fez parte, como mais um elemento, daquela forma social. Depois que viu a moça no vestido, depois que acompanhou toda a negociação, e que voltamos a conversar, Jussara me convidou a ver o vestido que ela desejava comprar para o Natal. Este não estava no box de sua mãe, mas no de outra feirante, próximo dali.

Compreendo que foi a compra do vestido vermelho por Amanda que levou Jussara a se pronunciar quanto ao que desejava para o Natal. No entanto, se considerarmos que a compra também é um processo intersubjetivo, pois partilhado, e que ocorre a partir de uma comunicação intersensorial - ou seja, de uma comunicação que também está pautada pelos jogos interpostos pelos sentidos do corpo enquanto elementos que cognitivamente dialogam -, podemos considerar que o que levou Jussara, que até então tinha estado sentada e calada, a conversar comigo, a manifestar seus desejos de maneira mais expansiva, não foi

\footnotetext{
Amanda, em entrevista concedida à pesquisadora na feira do Guamá. Belém, 16 dez. 2016. A partir do pensamento de Simmel compreendemos forma social como processo de sociação; ou seja, como o resultado de um processo construído, ininterruptamente, através das relações, das interações, que se estabelecem entre os mais diversos elementos e conteúdos (SIMMEL, 2006) presentes num dado contexto social.
} 
a compra em si, mas os processos contidos naquela interação e nos arranjos que funcionaram como gatilho, ou gatilhos, para a expressão de seus desejos.

Após a negociação, Jussara não mais permaneceu sentada em seu posto, menos ainda calada, e decidiu me apresentar o vestido que queria comprar, também para o Natal. Mas antes, era necessário justificar nosso novo eixo de diálogo, agora estabelecido por ela - depois de ter sido afetada ${ }^{8}$ pelo fenômeno da escolha do vestido de Amanda - e não mais estimulada por mim, como estava acontecendo antes da chegada de Amanda. A partir deste momento não preciso mais cativar Jussara, com o objetivo de compreendê-la - ação comum aos etnógrafos -, e invertemos esse papel de interlocução, pois Jussara convidou-me a ouvi-la. Assim, se iniciou uma outra e nova etapa de nosso diálogo a partir da compra feita por Amanda. "Porque é socialzinho, ela pode ir pra qualquer lado... ir pra uma festa... Coloca um sapato preto, pronto, tá perfeito" " disse-me ela, em referência ao vestido vermelho.

Jussara começou a indicar todos os pontos que qualificavam o vestido e a escolha de Amanda: "apesar dos decotes de trás e da frente do vestido, ele é bem socialzinho" - uma observação na qual podemos perceber certa reprovação moral $^{10}$; e aqui há outro elemento dessa forma social, o valor moral conferido ao fenômeno da escolha e compra de Amanda: "ele tem uma saia bem comportada, de uma boneca, não é de manga curta, pode ser usado com um sapato preto"11, que reforçava esse tom socialmente bem comportado, embora Amanda tenha adorado, pelo que me disse e pude observar, os decotes da frente e da parte de trás do vestido.

Ao justificar a compra feita por Amanda, Jussara colocava ali os elementos que não víamos materialmente, mas que estavam presentes nos atributos conferidos ao vestido no movimento comunicativo presente nas interações que conformavam aquela forma social. Não era o vestido, mas os elementos que o vestido materializava, e que justificavam a compra, aos seus olhos.

\section{OS PROCESSOS DE OBJETIFICAÇÃO PRESENTES NO DESEJO DO CONSUMO}

A partir do que foi observado em campo e evidenciado aqui, podemos ressaltar que as duas moças, Amanda e Jussara, observaram enfaticamente o

\footnotetext{
E aqui uso o termo ser afetada de Favret-Saada $(2005,2012)$, quando nos sentimentos afetados pelo fenômeno vivenciado e nos engajamos afetivamente e com todo o corpo em uma experiência.

9 Amanda, em entrevista concedida à pesquisadora na feira do Guamá. Belém, 16 dez. 2016.

10 Para contextualizar o lugar de fala também de Jussara, evidencio aqui que ela é evangélica e, durante nosso diálogo, demonstra restrições a determinados comportamentos que julga ir de encontro com os preceitos de Deus.

11 Jussara, em entrevista concedida à pesquisadora na feira do Guamá. Belém, 16 dez. 2016.
} 
vestido, novo e vermelho, que seria usado no Natal, na "festa familiar", uma celebração religiosa e afetiva, quando se comutam presentes e quando se supõe que cada um estará "bem vestido", como observou Amanda. Jussara observa que, para o evento, a pessoa deve "preparar-se" para estar bem, em sua melhor forma: "Ah, então quando a gente vai para uma festa com amigos, com a família. Você tem que se vestir bem, é bom" $"$. Esse prazer diante da coisa vestido, ou roupa, evidenciado por ambas as moças, mostrava uma maneira de sentir o mundo e de tomá-lo para si, que se consubstanciava no prazer de vestir a roupa não somente para si, mas para o outro, quando estabelecemos uma relação através do que portamos, ou seja, através das coisas que estão no mundo à nossa disposição e, ao lançarmos mão delas, geramos uma forma social que evidencia uma ética da estética ${ }^{13}$, uma forma de estar no mundo.

Diante do fenômeno da escolha, feita de maneira coletiva e complexa pois se Amanda escolheu o vestido vermelho foi porque muitos fatores, inclusive a participação dos presentes no seu ato de experimentar o vestido, puderam partilhar dessa escolha -, podemos observar que aquilo que compreendemos enquanto humanidade (MILLER, 1998, 2007), essa humanidade sugerida na escolha de Amanda e nos comentários de Jussara, que transforma a mercadoria, uma roupa a ser vendida, em um elemento de compartilhamento, está presente no ato do consumo. Amanda pretendeu compartilhar "seu estar no mundo" com esse vestido, com as outras pessoas com quem ela iria "estar no mundo" (MAFFESOLI, 1993, 1996) no Natal. O vestido era mais uma 'pitada de sal' nessas relações, mas uma pitada de sal muito importante e responsável no processo de sociabilidade.

Entendemos que a compra do vestido vermelho, mais caro, era um elemento que evidenciou uma lógica cultural em detrimento de uma lógica prática (SAHLINS, 1979) de consumo, "onde o consumo é concebido como um ato simbólico e coletivo" (BARROS; ROCHA, 2007, p. 12) dessas relações entre pessoas e coisas, quando da ordem das escolhas. São coisas que se destacam para tornarem-se elementos de partilha e, talvez, de generosidade entre os indivíduos que participam e participarão da escolha - pois o que corrobora para aquela escolha não são somente os elementos ali presentes e materializados, mas também, àqueles a quem Amanda deseja interagir na noite de Natal, os interlocutores eleitos de Amanda, esses que já estão participando da escolha do

\section{Ibid.}

13 Por estética, "compreendo a intersensorialidade presente na relação intencional de estar e usar o mundo, inclusive por meio da produção de analogias em relação à sensorialidade das pessoas ao nosso redor: a aisthesis é, também, um sentir-com-outros, um estar no mundo comum" (CASTRO, M., 2018, p. 128). 
vestido feita por ela, ainda que não estejam ali presentes, mas que participarão de sua noite de Natal.

Essa relação entre pessoas e roupas, entre o sujeito e a cultura material em que ele está inserido, faz com que o vestido vermelho se mova de seu estado de mercadoria ou bem alienável (MILLER, 2007; SIMMEL, 1993) para o estado específico da coisa (INGOLD, 2012) para atender a um sentido pessoal e social, ou, ainda, a um traço, a algo que nem sempre podemos qualificar, mas intuímos - aqui abordamos Derrida (1999) e seu conceito de traço, que se refere aos sentidos precários ou "ainda precários", pré-ontológicos, que não devem ou não podem ser transformados em sinais e/ou símbolos -, e que participa de nossas vivências e experiências.

Acompanhando o pensamento de Miller (1987, 2007, 2009), podemos observar que, ao participar do processo de interação, a cultura material - mais um elemento daquela forma social simmeliana (SIMMEL, 2006; CASTRO, F., 2017) - abaliza certa humanidade (MILLER, 2007) do e no indivíduo. Ao abalizar e corroborar para a construção de determinada humanização, essa cultura material também estará contribuindo para a construção de certa identificação (CASTRO; CASTRO, 2017); talvez não apenas contribuindo, mas evidenciando um processo de identificação já existente, e que colabora para a produção e/ou incremento do processo de reciprocidade ${ }^{14}$ (MAUSS, 1974). Assim, podemos observar como a roupa, os adereços, o equipamento e os instrumentos utilizados lá, bem como tudo o que é vendido, trocado e consumido (quando usados por aquele que os adquiriu), corroborarão para conformá-los no processo de objetificação. Objetificação, termo "usado para descrever uma série de processos consistindo em externalização (autoalienação) e sublatação (reabsorção) através da qual o sujeito de tal processo é criado e desenvolvido" (MILLER, 1987, p. 12, tradução livre) $)^{15}$.

O processo de objetificação seria, em nosso entendimento, o resultado do processo de identificação entre sujeito-objeto-intersubjetividade, ou ainda a sua concretude. Podemos dizer que o processo de objetificação concretiza o processo de identificação. No entanto, convém observar que o fato de concretizar ou realizar não implica em um enrijecimento ou estagnação: o processo é contínuo, gerando múltiplas realizações.

14 O processo sensorial e intersensorial, assim como o de identificação, tratado neste trabalho, é um processo que, em nossa compreensão, ocorre quando há reciprocidade, ou seja, quando há troca, e troca de sentidos, partilha de experiências, e nessa partilha, preocupação com o outro. Para chegarmos a essa compreensão de reciprocidade partimos de Mauss (1974) e da reflexão que Temple e Chabal (1995) faz sobre Mauss. Ou seja, diante do fenômeno aqui exposto, o processo de troca de sentidos no ato comunicativo implicou envolvimento e preocupação para com o outro.

15 Como no original: "The term is used to describe a series of processes consisting of externalization (self-alienation) and sublation (reabsorption) through which the subject of such a process is created and developed" (MILLER, 1987, p. 12). 
A busca pelo vestido de festa para o Natal na feira, a interação estabelecida pelo desejo de comprar e o desejo de vender, engendrou uma certa maneira de interagir que conformou certa sociação; mas essa forma social só estava sujeita à existência devido aos elementos que estavam lá e a conformaram: a coisa desejada - o vestido para o Natal, o freguês que queria o vestido para o Natal, os boxes na feira, o manequim em que o vestido estava exposto, os outros manequins que preenchiam o lugar visualmente, o conjunto de roupas expostas, os cabides de ferro, os armários, o vendedor da feira, o complexo industrializado da feira do Guamá, a presença de Jussara e outros que por ali passavam, a presença da pesquisadora, a venda, dentre outros elementos possíveis e forjados ali, como os processos sinestésicos, como a comunicação intersensorial ali produzida.

Usando uma metáfora para que possamos compreender melhor como essa forma social se conforma, ou seja, toma forma, podemos observar aquele lugar enquanto um "forno" que "assa" os elementos e conteúdo de maneira determinada para conformar aquela forma social que, sem ela, não teria sido possível. O consumo poderia ser o fogo - ou o vitalismo (MAFFESOLI, 1995, 2000) - que amalgamou esses elementos que conformaram essa forma social. Podemos também compreender esse lugar como a arena a que Douglas e Isherwood (2004) se referem, um espaço intenso de interações onde reverberam as sociações ou formas sociais.

Ainda acompanhando o pensamento de Miller (2007) e Douglas e Isherwood (2004), observamos que, se a cultura material evidencia uma humanização - e, talvez, promova-a, no que acreditamos, pois "é evidente que os bens têm outro uso importante: também estabelecem e mantêm relações sociais" (DOUGLAS; ISHERWOOD, 2004, p. 105) -, a compra do vestido e mesmo o seu "consumo" são feitos precisamente porque esses processos são capazes de engendrar interações e de corroborar a conformação de sociações. Dessa forma, o consumo da cultura material contribui para o incremento das interações e promove-o, colaborando para o processo de humanização do sujeito nas e das relações sociais.

\section{CULTURA MATERIAL E COMUNICAÇÃO INTERSENSORIAL}

Nesse sentido, podemos entender a cultura material utilizada e vivenciada na feira como um enunciado que reverbera na intersubjetividade e que, no fluxo interativo, participa da comunicação intersensorial e promove sentidos; assim, podemos intuir a formação de cadeias de sentidos que são gerados, promovidos e reverberados por esses fluxos comunicativos intersensoriais. 
Igualmente, não seria possível chegarmos a uma essência de sentido gerado pelo objeto, pois seu sentido é intermitente e continuamente construído, alterado e conformado nos processos interativos, e só nesses processos têm sentido.

Apesar da precariedade das instalações, da falta de luminosidade, do calor, os boxes são plenos de roupas. Manequins e cabides parecem saltar dos boxes, reduzindo o espaço físico do freguês, ocupando e enriquecendo sensorialmente aquele ambiente. Ainda que dona Gilda reclame de sua suposta precariedade quanto às coisas que vende - pois ela deseja viajar para comprar novas mercadorias para revender, reclamando da pouca opção que ela tem à venda -, seus boxes, assim como os das outras feirantes do local, me parecem cheios de roupas. Quatro dos boxes de dona Gilda ficam ao fundo do local, "Cinco

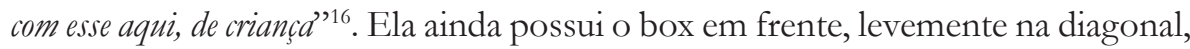
todos estão cheios de roupa. Em dezembro desse mesmo ano, dona Gilda já tinha adquirido mais um box ${ }^{17}$, ao lado daquele onde ficam expostas as roupas de criança, completando, assim, seis boxes de exposição e, se consideramos o box destinado ao vestuário, dona Gilda perfaz o total de sete boxes. Ao falar sobre o trabalho na feira, dona Gilda salienta a tranquilidade do lugar: "Ah, porque aqui é sossegado, né?! Tranquilo pra gente trabalhar. O movimento tá um pouco fraco, mas... dá, dá pra trabalhar aqui"18.

Aqui nos fica evidente, também, essa relação à qual Sahlins (1979) se refere, a proeminência da lógica cultural sobre a prática, ou ainda, no meu entender, como a lógica prática se conforma, se adequa, à lógica cultural.

Para termos uma ideia deste ambiente, trago a imagem abaixo, onde podemos ver dois boxes e meio que pertencem à dona Gilda. Do fundo, no primeiro plano da imagem à esquerda, vemos parte do box que tem o manequim sem braços com blusa-corpete vermelha e calça lycra-jeans e mais dois manequins infantis, abaixo, que o seguem ao fundo, tomando parte do lado direito da imagem, indo até o manequim de blusa amarela que está ao chão. Do lado direito, também podemos ver parte do quarto box de dona Gilda, destinado apenas para roupas infantis, sendo que, no interior do mesmo, também ficam expostas calcinhas e cuecas para adultos.

16 Ibid.

17 A aquisição de novos equipamentos por parte de dona Gilda ocorreu de maneira informal, em uma relação feirante - feirante, pois, de acordo com as normas estabelecidas pela Secretaria de Administração (SEAD), um feirante não pode ser permissionário de mais de três equipamentos/boxes em seu nome. Desta maneira, arranjos entre feirantes são feitos sem que a SEAD ou a administração da feira participe ou tenha conhecimento dessas negociações. Uma das possibilidades, o que ocorreu no caso de dona Gilda, é ela colocar os equipamentos que extrapolam o número de três ao qual ela tem direito, em nome de um membro de sua família. Este não é o único caso na feira. Ver M. Castro (2018).

18 Dona Gilda, em entrevista concedida à pesquisadora na feira do Guamá. Belém, 6 abr. 2016. 
Figura 1 - Vista diagonal dos boxes de dona Gilda

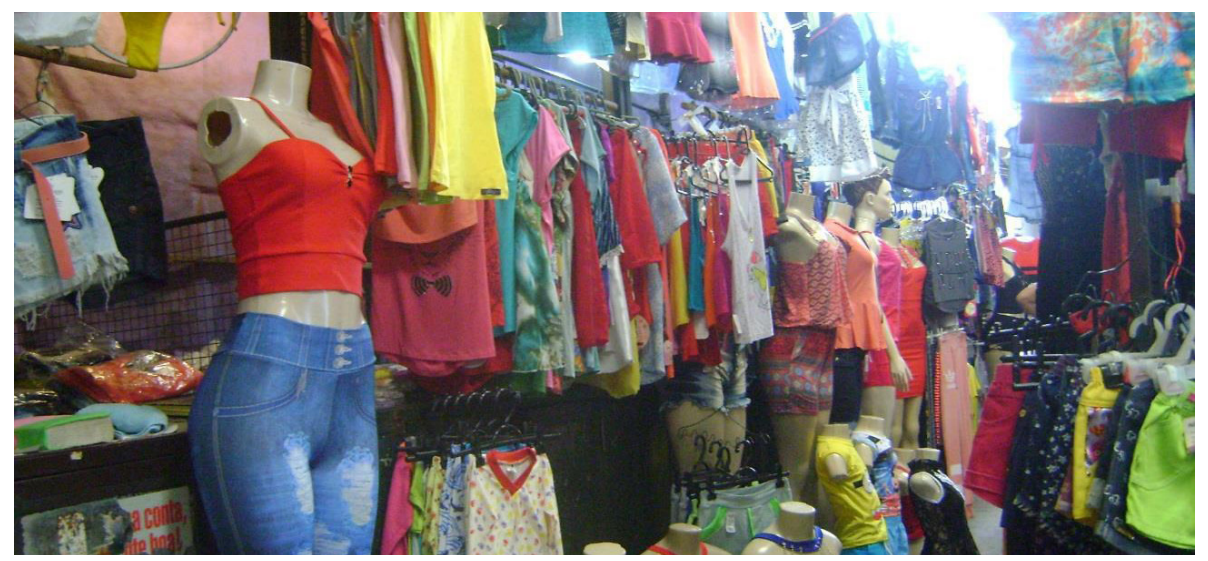

Fonte: Marina Castro, 16 dez. 2016.

Observamos que os sete boxes que dona Gilda possui se dividem de acordo com o gênero para o qual são voltadas as vestimentas. No da frente ela expõe roupas infantis, calcinhas e cuecas; ao lado, ela expõe roupa feminina, seu forte, segundo ela própria; o que fica em frente ao box de roupas infantis é utilizado como provador; três dos quatro boxes que ficam ao fundo são destinados somente a roupas femininas, e um único box é destinado às roupas masculinas (shorts e camisas são seu forte, mas ela também vende calças jeans masculinas), em sua maioria para adolescentes.

A parte interna de um desses boxes voltados para roupas femininas é ocupada por adereços, como brincos, colares, bolsinhas para festa, enfeites de cabelo e outros objetos do gênero.

Diferente de Madalena, outra feirante do local que não viaja para comprar mercadoria, dona Gilda, assim como as demais vendedoras de sua área, viaja e compra roupas para revenda, em especial, em Fortaleza, no Ceará, e a Santa Cruz, Pernambuco. Para dona Gilda, como também para dona Meire, é fundamental viajar. Quando dona Gilda não consegue viajar, sempre pede para uma das amigas trazer algo para ela:

Às vezes, quando não dá pra viajar, algumas amigas minhas que vão, trazem alguma coisa pra mim..., mas é melhor a gente ir mesmo, né?! Pra escolher... é melhor a gente mesmo. [...] É porque tem movimento um pouco fraco aqui, né?! Aí tá difícil da gente conseguir dinheiro pa... porque a despesa é alta, também, né?! Só de passagem a gente paga 500 reais... Ida e volta, porque a gente não vai só até Fortaleza, a gente vai até Santa Cruz, lá em Pernambuco... (Dona Gilda, em entrevista concedida à pesquisadora na feira do Guamá. Belém, 6 abr. 2016). 
Não consegui perceber essa falta de roupa da qual dona Gilda reclamava, mas, ao receber um freguês e não possuir o que ele procurava, uma calça jeans, eu acabei por compreender! O freguês, acompanhado do filho de dezesseis anos, ao chegar ao box, cumprimentou-a e o rapaz pediu sua bênção. Acreditei ser afilhado dela, mas não convinha perguntá-lo naquele momento. Interessante observar que, antes de olhar qualquer outro box, os dois se direcionaram para o de dona Gilda, ou seja, deram prioridade a ela, e só não compraram dela porque ali não tinha a mercadoria desejada, a calça jeans, nenhuma calça jeans masculina. Sistematicamente dona Gilda reclamava dos baques que teve nos últimos anos, da sociedade que fez com uma moça ao abrir uma "Loja de 10", "daquelas em que tudo que ali existe é vendido por dez reais"

Sem ter a calça a dispor para a venda, dona Gilda o encaminhou a uma amiga feirante, no box mais à frente, pediu a calça desejada pelo menino e acompanhou a venda, para que seu freguês fosse atendido e saísse satisfeito. Negócio fechado, das três calças ofertadas e experimentadas, ele ficou com uma.

Nessa relação rápida e aparentemente banal, podemos observar o respeito estabelecido entre as partes no ato da bênção de dona Gilda. O menino estende o braço e, ao levantá-lo, já sinaliza à dona Gilda o pedido da bênção, falando "bença", para que dona Gilda lhe dê a mão e o garoto a beije. Dessa maneira, dona Gilda retribui o beijo na mão do menino, ofertando-lhe sua bênção - o menino é seu afilhado, ainda que não lembre seu nome. Um fato que, talvez, justifique a ida direto a seu boxe e o aconselhamento na escolha da calça. Mas trataremos disso em um outro trabalho.

Outro movimento importante foi o comportamento de dona Gilda face à satisfação do afilhado. De acordo com as normas do local, nenhum feirante pode pegar o possível freguês pelas mãos, caso não tenha o que ele deseja em seu box, e o levar a uma feirante amiga. A norma ali estabelecida é deixar o freguês livre para ir onde lhe bem aprouver, sem precisar ser levado pelas mãos de uma feirante à outra. Dessa forma, dona Gilda queria satisfazer e acompanhar o desejo do afilhado, mas, ao mesmo tempo, não romper com a norma estabelecida.

\section{BREVE INTERPRETAÇÃO CONCLUSIVA}

Observando a relação de Gilda com Madalena, assim como a de Amanda com Sandra ${ }^{20}$, da mesma forma a de Gilda com o afilhado, podemos evocar aqui que essas relações estão, ali e naquele momento, pautadas pela interseção

\footnotetext{
19 Ibidem.

20 A amiga que chegara depois de Amanda para acompanhá-la na escolha.
} 
da cultura material. Observamos que a matéria - da mercadoria, transformada em coisa - porta qualidades que vinculam (MESKELL, 2005) feirante e freguês, pesquisador e pesquisado, madrinha e afilhado. A matéria, as coisas que vendem dona Gilda, dona Meire e Madalena, é o motivo, ali, de sua proximidade. O mesmo ocorreu entre dona Gilda e o afilhado, que há muito não se viam. Dona Gilda confessou-me ter temporariamente esquecido o nome dele. Ocorreu, também, com Amanda e com Jussara. No entanto, convém observar que os níveis de sociabilidade e de socialidade ${ }^{21}$ (SIMMEL, 2006) são diferentes, pois cada uma dessas pessoas funcionava como um elemento da forma a qual estavam construindo, ou corroborando para a construção. Ainda que eu tivesse, ali, um outro interesse, foi por meio daquelas coisas, daquela cultura material, que estabeleci contato com os frequentadores da feira e que acabei por colaborar com aquela sociação. Sem a coisa, sem aquela materialidade, teria sido mais difícil, talvez impossível, estabelecermos aquela interação.

Podemos observar que a troca, a compra e a venda, as relações recíprocas que estabelecemos e através das quais nos comunicamos estão permeadas pela comunicação intersensorial, ou seja, por aquela comunicação através da qual os sentidos são agentes fundamentais para a sua realização. De acordo com o contexto, essa interação produz elementos sensoriais e sensitivos que fazem parte dos processos sociais comunicativos, ainda que estes não sejam totalmente percebidos pelos indivíduos em interação.

Ressalto a relação oblíqua e não proposital entre Amanda e Jussara. A partir do encontro referido acima, observamos a disposição de ambas em atuar reciprocamente, em suas respectivas relações sociais, ou melhor, por meio de formas sociais convencionadas, na festa de Natal em família e com amigos. Os vestidos de ambas corroboravam na construção de determinada forma social sustentada pela reciprocidade de seus partícipes, mas isso só se tornou possível, na feira e na vida social, devido à intersubjetividade na qual estamos, todos, inseridos e na qual se produz a intersensorialidade ou, ainda, a comunicação intersensorial, aquela que dispensa o diálogo formal, superando-o.

21 A partir de Simmel (2006), compreendemos os processos de sociabilidade e socialidade como processos de sociação que conformam a própria forma social. Ou seja, processos que produzimos no mundo da vida. No entanto, importante observar que os processos de sociabilidade, assim como o de socialidade são estabelecidos em graus de envolvimento emocional e sensível de diferente ordem. Sociabilidade engendra um envolvimento afetivo diretamente pautado pela relação entre o $e$ e o tu/outro, quando o outro tem importância em primeiro plano na interação. $\mathrm{O}$ de socialidade engendra um envolvimento pautado por um interesse no qual o outro tem lugar em segundo plano, e o objetivo não é a relação entre o en e o tu/outro, e sim, em um terceiro elemento, uma coisa, por exemplo (CASTRO, M., 2020). 


\section{REFERÊNCIAS}

BARROS, C.; ROCHA, E. Lógica de consumo em um grupo das camadas populares: uma visão antropológica de significados culturais. In: ENCONTRO DA ASSOCIAÇÃO NACIONAL DE PESQUISA E PÓS-GRADUAÇÃO EM ADMINISTRAÇÃO, 31., 2007, Rio de Janeiro. Anais [...]. Rio de Janeiro: EnANPAD, 2007. p. 1-16.

CASTRO, F. F. Temporalidade da comunicação na sua quotidianidade. In: MUSSE, C. F.; VARGAS, H.; NICOLAU, M. (org.). Comunicação, mídias e temporalidades. Salvador: Edufba, 2017. p. 97-116.

\section{CASTRO, M. R. N. Socialidades e sensibilidades no quotidiano da}

Feira do Guamá: uma etnografia das formas sociais do gosto. 2018.

Tese (Doutorado em Antropologia) - Programa de Pós-Graduação em Antropologia, Universidade Federal do Pará, Belém, 2018.

CASTRO, M. R. N. Comprando na feira: experienciando a carne do Mundo. Etnografia e comunicação intersensorial. In: ENCONTRO ANUAL DA COMPÓS, 24., 2020, Campo Grande. Anais [...]. Campo Grande: Universidade Federal de Mato Grosso do Sul, 2020. p. 1-13.

CASTRO, M. R. N.; CASTRO, F. F. Banalidade e intersubjetividade na arte. Porto Arte, Porto Alegre, v. 22, p. 181-193, 2017.

CLASSEN, C. Foundations for an anthropology of the senses. International Social Science Journal, [s. l.], n. 153, p. 401-12, 1997.

CORBIN, A. Histoire et anthropologie sensorielle. Anthropologie et Sociétés, Paris, v. 14, n. 2, p. 13-24, 1990.

CORBIN, A. Histoire et anthropologie sensorielle. In: CORBIN, A. Le temps, le désir et l'horreur, Paris: Aubier, 1991. p. 227-240

DERRIDA, J. Gramatologia. São Paulo: Editora Perspectiva, 1999.

DOUGLAS, M.; ISHERWOOD, B. O mundo dos bens: uma antropologia do consumo. Rio de Janeiro: Editora UFRJ, 2004.

FAVRET-SAADA, J. Ser afetado. Caderno de Campo, Araraquara, n. 13, p. 155-161, 2005.

FAVRET-SAADA, J. The way things are said. In: ROBBEN, A. C. G. M.; SLUKA, J. A. (Ed.). Ethnographic fieldwork: an anthropological reader. Malden, Massachusetts: Blackwell, 2012. p. 528-539. 
HOWES, D.; MARCOUX, J-S. Introduction a la culture sensible.

Anthropologie et Sociétés, Paris, v. 30, n. 3, p. 7-17, 2006.

INGOLD, T. Trazendo as coisas de volta à vida: emaranhados criativos num mundo de materiais. Horizontes Antropológicos, Porto Alegre, ano 18, n. 37, p. 25-44, 2012.

MAFFESOLI, M. La contemplation du monde: figure du style communautaire. Paris: Grasset/Frasquelle. Le Livre de Poche, Biblio-Essais, 1993.

MAFFESOLI, M. La transfiguration du politique. Paris: Le Livre de Poche, 1995.

MAFFESOLI, M. Éloge de la raison sensible. Paris: Grasset, 1996.

MAFFESOLI, M. O tempo das tribos: declínio do individualismo nas sociedades de massa. Rio de Janeiro: Forense Universitária, 2000.

MAUSS, M. Ensaio sobre a dádiva. Forma e razão da troca nas sociedades arcaicas. In: MAUSS, M. Sociologia e Antropologia. São Paulo: EDUSP, 1974. v. 2. p. 183-185.

MESKELL, L. Introduction: object orientations. In: MESKELL, L. (Ed.). Archaeologies of materiality. Oxford: Blackwell Publishing Ltd, 2005. p. 1-17.

MILLER, D. Material culture and mass consumption. Londres: Basil Blackwell, 1987.

MILLER, D. A theory of shopping. Ithaca: Cornell University Press, 1998.

MILLER, D. Consumo como cultura material. Horizontes Antropológicos, Porto Alegre, ano 13, n. 28, jul/dez, 2007, pp. 33-63.

MILLER, D. The comfort of things. Cambridge: Polity, 2008.

MILLER, D. [Entrevista concedida a] Catarina Morawska Vianna e Magda dos Santos Ribeiro. Sobre pessoas e coisas: entrevista com Daniel Miller. Revista de Antropologia, São Paulo, v. 52, n. 1, p. 415-439, 2009. Disponível em: https:// www.revistas.usp.br/ra/article/view/27343/29115. Acesso em: 11 nov. 2020.

PINK, S. Doing sensory ethnography. Londres: SAGE, 2009.

PINK, S. What is sensory ethnography. National Center for Research Methods, [s. l.], 2010. Disponível em: https://www.ncrm.ac.uk/resources/ video/RMF2010/pages/18_Sensory.php. Acesso em: 02 dez. 2020.

SAHLINS, M. Cultura e razão prática. Rio de Janeiro: Zahar, 1979. 
SIMMEL, G. Sociabilidade: um exemplo de sociologia pura ou formal. In:

MORAIS FILHO, E. (org.). Georg Simmel: sociologia. São Paulo: Ática, 1993. p. 165-181.

SIMMEL, G. Questões fundamentais da sociologia. Rio de Janeiro: Zahar, 2006.

TEMPLE, D.; CHABAL, M. La réciprocité et la naissance des valeurs

humaines. Paris: L'Harmattan, 1995. 
